\title{
Accessibility evaluation of topographic maps in the National Library of Poland
}

\author{
Marta Kuźma ${ }^{\mathrm{a}, *}$, Albina Mościcka ${ }^{\mathrm{a}}$ \\ ${ }^{a}$ Military University of Technology, Marta Kuźma, marta.kuzma@wt.edu.pl, Albina Mościcka, albina.moscicka@wat.edu.pl \\ * Corresponding author
}

Keywords: topographic maps, digital library, accessibility evaluation

\begin{abstract}
:
Digital libraries are created and managed mainly by traditional libraries, archives and museums. They collect, process, and make available digitized collections and data about them. These collections often constitute cultural heritage and they include, among others: books (including old prints), magazines, manuscripts, photographs, maps, atlases, postcards and graphics. An example of such a library is the National Library of Poland. It collects and provides digitally available data of about 55,000 maps.
\end{abstract}

The effective use of cultural heritage resources and information from National Library of Poland gives the prerequisites and challenges for multidisciplinary research and cross-sectoral cooperation. These resources are an unlimited source of knowledge, constituting value in themselves but also providing data for many new studies, including interdisciplinary studies of the past. Information necessary for such research is usually distributed across a wide spectrum of fields, formats and languages, reflecting different points of view, and the key task is to find them in digital libraries.

The growth of digital library collections requires high-quality metadata to make the materials collected by libraries fully accessible and to enable their integration and sharing between institutions. Consequently, three main metadata quality criteria have been defined to enable metadata management and evaluation. They are: accuracy, consistency, and completeness (Park, 2009, Park and Tosaka, 2010). Different aspects of metadata quality can also be defined as: accessibility, accuracy, availability, compactness, comprehensiveness, content, consistency, cost, data structure, ease of creation, ease of use, cost efficiency, flexibility, fitness for use, informativeness, quantity, reliability, standard, timeliness, transfer, usability (Moen et al., 1998). This list tells us where errors in metadata occur, which can result in hindering or completely disabling access to materials available through a digital library.

Archival maps have always been present in the libraries. In the digital age, geographical space has begun to exist in libraries in two aspects: as old maps' collections, as well as a geographic reference of sources other than cartographic materials. Despite many experiences in this field, the authors emphasize that the main problem is related to the fact that most libraries are not populating the coordinates to the metadata, which is required to enable and support geographical search (Southall and Pridal, 2012).

During this stage the concept of research is born and the source materials necessary for the realization of this concept are collected. When using archival maps for such studies, it is important to be aware of detailed literature studies, including cartographic assumptions, the course and accuracy of cartographic works, the way of printing, the scope of updates of subsequent editions, and the period in which the given map was created. The ability to use cartographic materials also depends on the destination map. The awareness of the above issues allows researchers to avoid errors frequently made by non-cartographers, i.e. to prevent comparing maps on different scales and treating them as a basis for formulating very detailed yet unfortunately erroneous conclusions. Thus, one of the key tasks is to find materials that are comparable in terms of scale and that cover the same area and space in the historical period of interest.

The research aim is to evaluate the quality of topographic maps metadata provided by the National Library of Poland, which are the basis for effective access to cartographic resources.

The first research question is: how should topographic maps be described in metadata to enable finding them in the National Library of Poland? In other words, what kind of map-specific information should be saved in metadata (and in what way) to provide the proper characteristic of the spatially-related object?

The second research question is: which topographic maps have the best metadata in such a way as to give the users the best chance of finding the cartographic materials necessary for their research?

The paper will present the results of research connected with finding criteria and features to metadata evaluation, it means how archival maps are described. For the maps, it is a set of map features, which are collected in the metadata. This set includes the geographic location, map scale, map orientation, and cartographic presentation methods. The conducted evaluation refers to the quality of metadata, or, in other words, the accessibility of archival cartographic resources. 